I am doubtful of the expediency of resorting to a canula and plugging the wound in cases of hæmorrhage, and have not resorted to it. Hæmorrhage on the ninth day occurred in a middle-aged man in whom I had been obliged to extend the incision through the prostate to remove a large stone. It recurred at intervals, large clots being voided after straining. He was easy for a time after the clots passed; gradually a feeling of distension of the bladder came on, followed by straining efforts to empty the bladder and rectum, which ended in the expulsion of a coagulum. This continued all night. In the morning he was faint and pallid, and there was still an oozing of venous blood. The bleeding being evidently from a deep source, I was obliged to content myself with clearing away the clots, exposing the parts to air, raising the pelvis, and applying cold water. Happily there was no further return of the bleeding. In a boy, aged eight, there having been nothing remarkable in the operation, rather severe bæmorrhage occurred on the 20 th day, and again on the $28 \mathrm{th}$. I removed the clots, but could not discover the source of the bleeding. It did not return. In another lad, aged twelve, whose case will be related subsequently, there was bleeding from a deep source, which re. turned on the third and seventh day, and probably contributed to the fatal result.

I do not usually insert a canula after the operation, not having found the need of it, and being apprehensive of the end escaping from the bladder and causing irritation in the surrounding cellular tissue.

The after treatment usually consists in taking care that the drawsheet is frequently changed, so as to keep the parts dry, and in protecting the serotum from moisture, in regulating the diet according to the habits and requirements of the patient, and in meeting symptoms as they arise. After severe operations urine is sometimes sparingly secreted, and may not appear for some hours. If none have flowed in six or seven hours, I insert my finger through the wound into the bladder, to ensure a free passage; and if there then be difficulty in voiding it, I fasten a canula in the wound. Sometimes, when the wound is healing, there is inability to pass urine, requiring the use of the catheter. In a man aued sixty-two, where this was attended with a good deal of pain, and the urine was turbid and ammoniacal, I re-opened the wound with my finger, and left a canula in for $\Omega$ few days, after which the urine improved, the wound was allowed to heal again, and the difficulty and pain did not return. In a man aged fifty-four, where the stone was large, a fortnight after the operation, when the urine was beginning to pass by the urethra, there was a good deal of uneasi. ness about the bladder and pain in micturition; the urine alkaline and loaded with tenacious mucus. I drew off the urine by a large gum-elastic catheter through the urethra, and injected warm water into the bladder, so as to wash out the viscus thoroughly; I did this, at first, twice, afterwards once a day. He was relieved the first time, and the improvement continued, so that in a fortnight the treatment was no longer necessary, the urine being voided naturally and without pain.*

I have performed the high or supra-pubic operation of lithotomy once successfully ; the recto-urethral operation once, for oncysted calculus, with fatal result ; $\ddagger$ and the lateral operation 89 times, with the loss of 7 patients. In 41 of the lateral cases the patients were adults ( 8 between twenty and fifty, 20 between fifty and sixty, 13 between sixty and seventy.five); of these 5 died. In 48 cases the patients were under twenty (3 were ten years old, and 33 under ten); of these 2 died. The cases were not selected, perhaps not so much as ought to have been ; for it will appear from the narrative of the fatal cases that in some ( 3 or 4 ) the operation was barely warranted, and was undertakes only to give a chance of recovery from an extreme state. In one of the fatal cases the bladder was rup. tured with the forceps, and one patient died of erysipelas.

The favourable result in so large a proportion of adults (5 fatal in $41=1$ in 8 ) is attributable partly to the class of patients. Nearly all were agricultural labourers, and they certainly bear operations well. The average size of the calculi was not great. In 9 only was the weight more than an ounce; that of the largest was $6 \frac{1}{2}$ oz., that of the next largest $20 z .5 \mathrm{dr}$.;

* It is worthy of remark that, in this case, on several occasions, there passed through the eatheter, and lodged in it, ragged masses of soft white substance, like lymph, with gritty earthy matter entangled in it. These would, not unlikely, have remained in the bladder, and furnished nuclei for another stone, if they had not been washed away. Masses of this sort forming in the bladder, particularly after a severe operation, are probably not unvalue in showing the importance of watching after an operation, and washing value in showing the importance of watching after an operation, and washing
out the bladder if it seems necessary.

ciation," vol. xvii. " p. 103 .

₹ Case related in "Association Medical Journal," Feb. 23, 1856. in 12 it was between half an ounce and an ounce, and in all the others less than half an ounce. In these days of increased medical supervision and better diagnosis, it must be supposed that cases are operated upon at an earlier period than formerly; and there should be a corresponding improvement in the sta. tistics of the operation.

The particulars of the fatal cases will be given in my next communication.

\section{FATAL H FMORRHAGE AFTER DELIVERY, CAUSED BY THE PRESENCE OF A PLACENTAL UTERINE POLYPUS.}

BY JOHN S. BEALE, EsQ, M.R.C.S.

ON the 8th of last August I received a summons to make a post-mortem examination of the body of a female who had died a few hours after delivery. Her medical attendant being out of town, she was delivered by his "locum tenens ;" and this circumstance, aided by the loquacity of a female friend, caused the inquest to be called. The evidence given was that the labour was lingering, the woman being faint and exhausted; and that she died about three or four hours after having given birth to a fine large male child. Before detailing the postmortem appearances, I may premise that I had delivered her instrumentally some eight years previously, she being in a very exhausted state through protracted labour and the large size of the child.

The body was well nourished; features calm; lips blanched; lungs healthy; heart large, pale, and flabby; no blood in the auricles or ventricles. A coagulum extended into the aortic orifice. The pericardium contained about six drachms of fluid. There was about two pints of fluid tinged with blood in the cavity of the abdomen. Liver pale; stomach pale, and containing a little tea; intestines distended with flatus; kidneys and other viscera healthy. Rising above the coils of intestines, and pushing them aside, was seen the uterus, largely distended, and about the size of the uterus at the fifth month of gestation. The uterus was opened by an incision shaped like the letter $Y$, which exposed a fleshy tumour some seven inches in length, terminating in and surrounded by a very large coagulum of dark firm blood closely adherent to the tumour, and blocking up and distending the cavity of the uterus, and projecting within two inches of the external labia. The coagulum was carefully removed, and weighed over twenty ounces. The tumour was now distinctly seen attached by a pedicle over one inch in diameter to the right side of the fundus of the uterus. The pedicle was about three inches in length, and gradually expanded into a glossy, soft, even mass about three inches in breadth and seven inches in length. No lesion of the uterus or vagina was discoverable. The pedicle was firmly attached to the uterus, and was round in form; and the wall of the uterus was injured in its removal, so close was the union. On washing the tumour and incising it, it presented, when placed in water, the cotyledonons structure (only smaller) of the placenta, with the usual spongy cellular tissue.

Never having seen, heard, or read of such a case previously, I gave my evidence to the effect " that the presence of the tumour prevented the contraction of the womb, encouraged the formation of the coagulum, and caused death by the abstraction of the blood from the general circulation, which, acting on a female of feeble powers, was sufficient to cause death." $A$ verdict to this effect was returned. I sent a portion of the structure to Dr. Kirkes, who kindly examined it microscopically, and wrote " that the structure resembled placenta," and tbrew out the suggestion of a portion of placenta left in utero. The attachment by pedicle, and the mark of the placenta proper a little to the left of its neck, with the smooth rounded shape of the mass, in my humble opinion negatived such a view. Dr. Kirkes very courteously at the same time directed my attention to an ahle paper written by Dr. Stadfeldt, of Copenhagen, and published in the November number of the Dublir Quarterly Journal of Medical Science, page 492 : "Dr. Stadfeldt states that Dr. Brann entertains the opinion that the fibrinous polypi are remains and products of pregnancy; he thinks, moreover, that they are not only consequences of abortions, abortive ova, mola carnosa, and retention of the placenta after a non-viable foetus, but that also the remains of the pla. 
centa of a fotus born at the full time may give rise to the formation of polypoid bodies in the uterus," \&c. Dr. Stadfeldt gives a case in illustration, with the post-mortem appearances. He says, "The cavity of the uterus was enlarged, filled with an ovum-like body of the size of a large walnat, which, from its porous, fibrous consistence and reddish.grey colour, was evidently composed of placental structure." The report of such case will, I have no doubt, open a wide field for medical observation. The presence of such tumours may frequently be the means of causing death by obstruction to the proper closure of the womb; and even, as in the case detailed in this imperfect paper, be the means of soliciting official inquiry. sincerely trust that this will meet the eyes of some member of the profession who will be able to expound the formation of such tumours, and place upon record the results of his experience regarding their existence and formation.

Paddington-green, April, 1864.

\section{ON UNUNITED FRACTURES.}

\section{BY W. H. B. WINCHESTER, Esq., F.R.C.S.}

Is a paper read before the Royal Medical and Chirurgical Society, and reperted in THE LANCET of the 19 th ult., Mr. Bickersteth proposes a new operation for the treatment of ununited fractures-a proceeding bold and novel, if not altogether original, and which received from the members present unani. mous praise. It is to be regretted, however, that a subject of wuch great importance, whilst receiving so much deliberate attention, should not have been viewed in all its bearings instead of being confined to the consideration of the proposed operation only. There is an aspect, and that of far deeper in. terest both to the profession and the public-viz., prevention, which seems to have been entirely lost sight of. Surely efforts for the total prevention of such cases would be far more credit. able to modern British surgery than attempts at cure by such formidable and questionable means. Prevention is not so diffi. cult or impossible a task that the necessity for resorting to such extreme measures may not be altogether avoided.

Ununited fractures are but simple fractures allowed to pass from stage to stage, either from want of professional assistance, or with it through defective means at command, until nature, exhausted by repeated fruitless efforts, seems incapable of renewing them, unless stimulated by some such extraordinary proceeding as the one proposed. Does not this clearly show the necessity for greater efforts during the early or preventive stage? For if enfeebled nature is able to accomplish the double task of repairing the mischief occasioned by accident as well as by art, she could much more readily perform the one duty only when in possession of healthy vigour. Entertaining these views, I cannot accord the same amount of anqualified praise to the suggestion that it received from those members of the Society who took part in the discussion. Indeed, I can scarcely consider it an improvement, for the risk, to say nothing of the practical difficulty of accomplishing it, far outbalances the success which may occasionally attend its performance. I have no hesitation in expressing my belief that, in any case in which a cure can be effected by it, the same may be as readily, if not more so, accomplished without it. I cannot, therefore, see any adrantage to be gained by its adoption. The unfarourable result of the second case recorded by $\mathrm{Mr}$. Bickersteth must be attributed to the constitutional disturbance it excited, and consequently amputation in that instance would have been a far preferable expedient. The operation itself is by no means so easy of performance as would appear from the description of it. To preserve the ends in exact position whilst drilling oblique holes through them, must be attended with extreme difficulty, and the injury necessarily inflicted on the soft parts may result in tetanus or pyæmia, as pointed out by Mr. Moore. The suggestion, nevertheless, as an original and independent effort to surmount a manifest difficulty, is not undeserving of praise.

The varied and uncertain results of the treatment of fractures, as at present conducted, often bring unmerited disgrace on the profession. Mr. Skey, in the introductory remarks to his record of cases recently published in THR LANCkT, laments the want of uniformity of practice, not only in different institutions, but amongst the different surgeons of the same institution, and, I would add, in the practice of each individual surgeon. Taking $\mathrm{Mr}$. Skey's record of his own cases, we find fractures of the thigh, some treated with the long, straight splint, and some without it ; fractures of the leg, some treated without splints, and some with ; simple fractures treated in one way, and compound in another,-showing the greatest diversity and uncertainty of practice. All must admit, therefore, that the subject is deserving the serious reconsideration of the profession, with the view of establishing a fixed and uniform system of treatment.

It is now upwards of eleven years since $I$ brought to the notice of the profession, in a short paper read before the MedicoChirurgical Society, a method of treatment which is fully capable of effecting all that can be desired, affording a fixed and unerring principle, rendering all cases, whether simple or compound, equally amenable to treatment, and which will do all that art can do for the entire prevention of ununited fractures. It has been practically tested by Mr. De Morgan in the Middlesex Hospital, and the principle recognised and adopted by the international jurors. Being then both theoretically and practically correct, it demands general adoption.

I would call Mr. Bickersteth's attention to a little instrument I invented many years ago for a case of double fracture of the humerus, and which readily accomplished that which every other means at my command had failed to effect. In a case of tardy union of the thigh, occurring in the practice of $\mathrm{Mr}$. Coulson at St. Mary's Hospital, and recorded in THE LANCET for October 14th, 1854, p. 316, it also perfectly succeeded, and would doubtless have done the same in those cases of ununited fracture alluded to in Mr. Bickersteth's paper.

I shall forward shortly to THE LANCET a sketch of my instrument, which obtained the approval of the international jurors, adapted for the thigh, leg, and arm, with a description of it. I may here briefly remark that it is applicable to either simple, compound, comminuted, or oblique fractures; is perfect in its retentive power, embracing the limb only at the exact points necessary for complete security, and therefore, if used from the first, will not only shorten the duration of suffering, but effectually prevent the occurrence of ununited fractures.

Knowl Hill, April, 1864.

\section{(3) alirrot}

OF THE PRACTICE OF

\section{UEUICINE AND SURGERY IN THE}

\section{HOSPITALS OF LONDON.}

Nulla autem est alia pro certo noscendi via, nisi quamplurimas et morborum, et dissectionum historias, tum aliorum, tum proprias collectas hajere, et inter se comparare.-Monenexi De Sed, et Caus. Morb., lib. iv. Procemiam.

\section{ST. GEORGE'S HOSPITAL.}

granular DEGENERATION OF THE KIDNEY, FATAL FroM TYPHUS (?) FEVER ; OBSTRUCTION OF THE CYSTIC DUCT BY A GALL-STONE, GIVING RISE TO DROPSY OF THE GALL-BLADDER.

(Under the care of Dr. PAGE)

THe following case is chiefly interesting from the fact that the cystic duct was obstructed by a large gall-stone, which caused an absence of bile in the gall.bladder, that fluid being replaced by a quantity of transparent and perfectly colourless mucus (?). On reference to the most comprehensive work in our language on Gall-stones-namely, that by Dr.Thudichumit will be seen that the chapter on the Anatomy of Gall-stone Disease contains an interesting and instructive account of the changes which calculi produce in the gall-bladder. If the cystic dact is blocked up, as in the case now recorded, no bile can find its way into the gall-bladder, and a secretion may pour out from the mucous membrane-the result of irritation-and fill up the cavity. Dr. Thudichum describes an instance like the following (p. 192), where there was an absence of bile, and evidently an obstruction of the cystic duct for some time; for the gall-bladder had become what is termed dropsical. The 